\title{
Hexacosanoate Contents in Japanese Common Foods
}

\author{
Kazue KaWAHARA, Yukari IWASAKI, Yasumi HARADA, \\ Yumi MARUYAMA, Sawako OnO, Kyoko KanJA, \\ Harumi SASAI, Saburō NANBA, ${ }^{1}$ Hiroyuki NAKANO, \\ and Takashi KUSAKA ${ }^{2, *}$ \\ ${ }^{1}$ Kawasaki College of Allied Health Professions, 316 Matsushima, \\ Kurashiki 701-01, Japan \\ ${ }^{2}$ Department of Biochemistry, Kawasaki Medical School, 577 Matsushima, \\ Kurashiki 701-01, Japan
}

(Received June 20, 1988)

Summary Recently, a diet enriched in oleate and moderately restricted in hexacosanoate $(\mathrm{C} 26: 0)$ was found effective to reduce the plasma very long chain fatty acid (VLCFA) levels in patients with adrenoleukodystrophy (ALD), an X-linked disorder characterized by demyelination of the adrenal cortex and cerebral white matter, and accumulation of saturated VLCFA, particularly C26:0, in tissues of the demyelination. The information about the C26:0 content in Japanese food was, however, almost nil except for one report about foods in the USA, but this did not include some Japanese common foods. With the hope of treating an ALD patient in our hospital, C26:0 contents in Japanese common foods (42 items) were measured. In our case, a one-hour direct transesterification method was used to obtain methylesters of total fatty acids in foods and they were applied directly to a selected ion monitoring gas chromatography-mass spectrometry for the quantitative $\mathrm{C} 26: 0$ analysis. The $\mathrm{C} 26: 0$ content in nuts and seeds as well as in fats and oils was found to be significantly higher than in other foods; the content was highest in peanuts. The content in almost all kinds of examined fishes, the common protein foods in Japan, was relatively low. From these data and that in the national nutrition survey in 1986, the daily intake of C26:0 from the average Japanese diet could be estimated to be $12-36 \mathrm{mg}$. It can be recommended, therefore, that nuts and seeds as well as fats and oils should be restricted as severely as possible from the diet of ALD patients in Japan in order to keep daily C26:0 intake below $10 \mathrm{mg}$ as recommended in the USA.

Key Words hexacosanoate, very long chain fatty acid, adrenoleukodys-

${ }^{1}$ 河原和枝，岩崎由香利，原田泰美，丸山由美，小野佐和子，神社香子，笹井治美， 難波三郎, ${ }^{2}$ 中野裕之, 日下喬史

* To whom correspondence should be addressed. 
trophy, oleate, transesterification, selected ion monitoring gas chromatography-mass spectrometry, nuts and seeds, fats and oils, fishes

Adrenoleukodystrophy (ALD) is an X-linked disorder characterized by demyelination of cerebral white matter and adrenal cortex as well as accumulation of saturated very long chain fatty acids (VLCFAs) composed of around 26 carbons in tissues of the demyelination. The pathogenesis of VLCFA accumulation in ALD is, however, not sufficiently elucidated; some reports $(1,2)$ attributed it to endogenous factors, especially a decrease in enzyme activity of the VLCFA-oxidation system, while another(3) demonstrated an exogenous $\mathrm{C} 26: 0$ incorporation into the patient's brain. Regarding the treatment for this disease, Van Duyn and his colleagues (4) tried at first restricting VLCFA intake in the patients but found that it did not normalize the plasma levels of C26:0. Next, Rizzo et al. (5) and Moser et al.(6) achieved significant reductions in plasma VLCFA levels of the patients with diets enriched in oleate $(\mathrm{C} 18: 1)$ along with a restriction in $\mathrm{C} 26: 0$. Recently we received one ALD patient in our hospital and we wanted to restrict the $\mathrm{C} 26: 0$ content in his diet; however, information about C26:0 content in Japanese common foods was almost nil unless we refer to the report of Van Duyn group (4) about foods in the USA but this did not include some Japanese common foods, especially fishes. We thus measured the C26:0 contents in Japanese common foods, with the hope of treating ALD patients in Japan including ours.

\section{METHODS}

Foods examined. Ten food groups comprising 42 items easily obtainable in our district (Table 1) were examined for C26:0 content. We selected, for the examination, meat and fishes which were as fresh as possible, checking the slaughter or capture date. Vegetables, fats and oils, and all other foods examined were also selected on the same basis.

Reagents. The authentic methyl pentacosanoate (Me-C25:0), and Me-C26:0 were the product of Sigma Chemical Co. All organic solvents used were of the quality for HPLC. All other chemicals were reagent grade.

Preparation of methylesters of total fatty acids from foods. Fruits and vegetables were cut with a knife into small pieces and lyophilized overnight before use. Other foods as well as the lyophilized foods as above were weighed and duplicate samples (each $0.1-0.2 \mathrm{~g}$ ) were used for the preparations of methylesters of total fatty acids. These preparations were carried out according to the method of Lepage and Roy(7) except for using pentacosanoate internal standard solution ( $5 \mu \mathrm{g} \mathrm{C} 25: 0$ dissolved in $2 \mathrm{ml}$ of methanol-benzene, $4: 1, \mathrm{v} / \mathrm{v}$ ), instead of tridecanoate, for the one sample and using non-internal standard solution (just $2 \mathrm{ml}$ of methanol-benzene, $4: 1, \mathrm{v} / \mathrm{v}$, was used) for the other sample.

Quantitative analysis of $C 26: 0$ in the methylesters of total fatty acids. The 


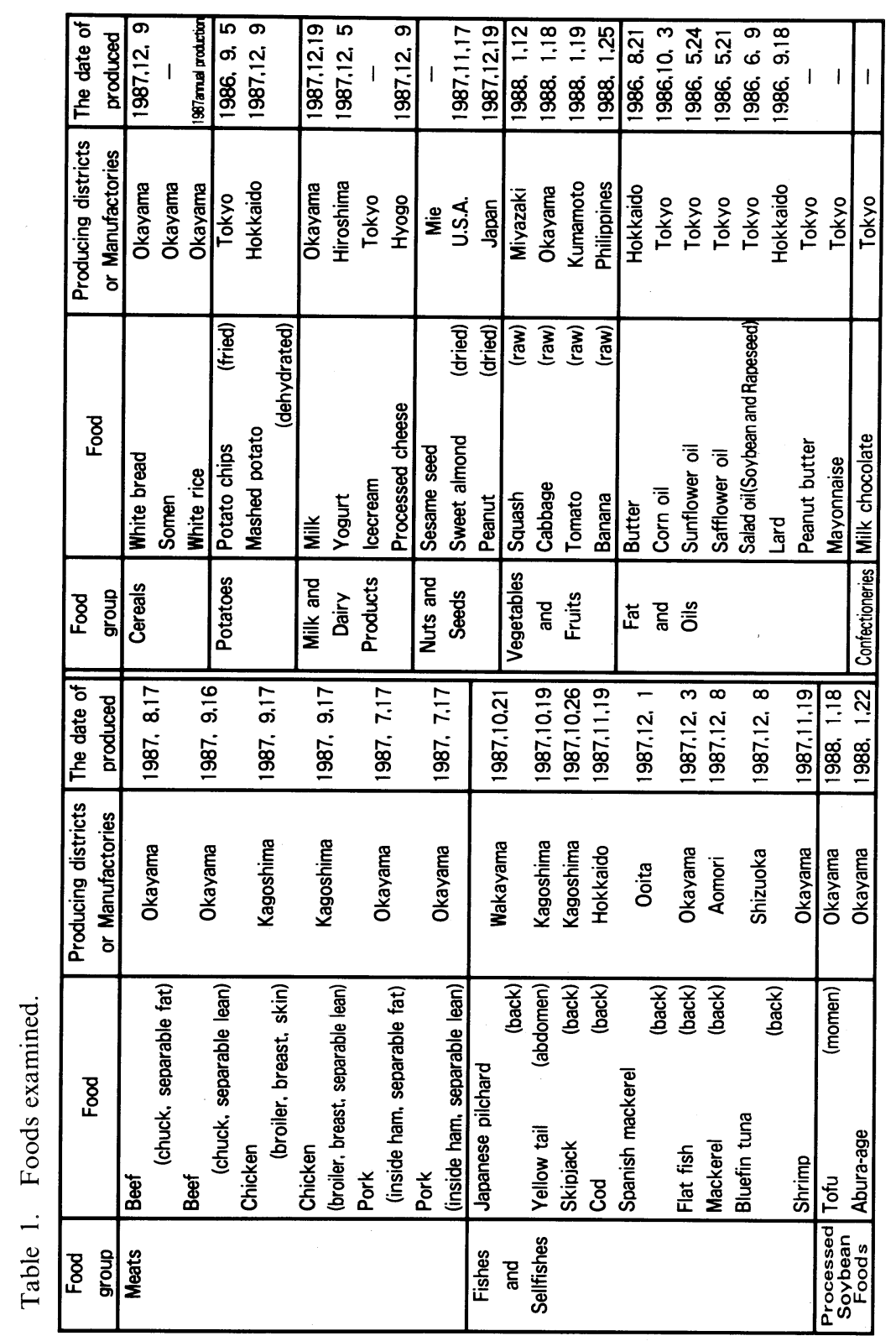


Table 2. Calculation of real peak-area ratio $(R)$.

$$
R=\frac{a b}{b-a}
$$

$a$ : apparent peak-area ratio with internal standard.

$b$ : apparent peak-area ratio without internal standard.

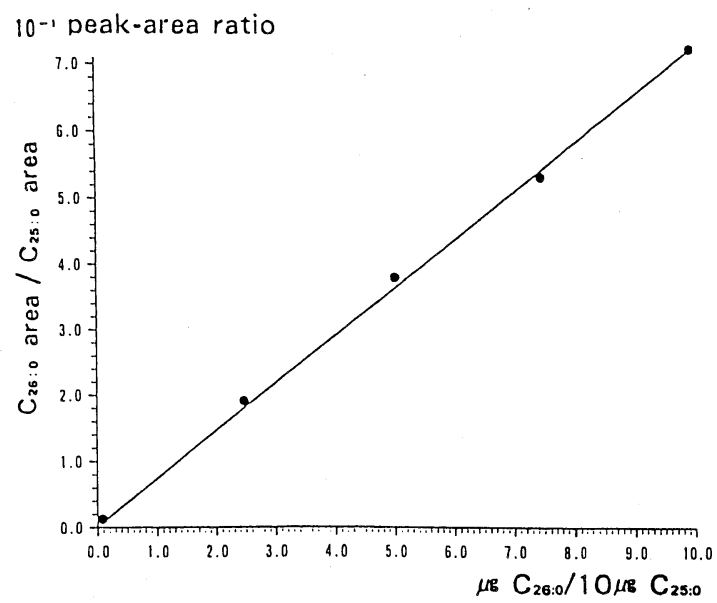

Fig. 1. Calibration curve.

Retention time (min)
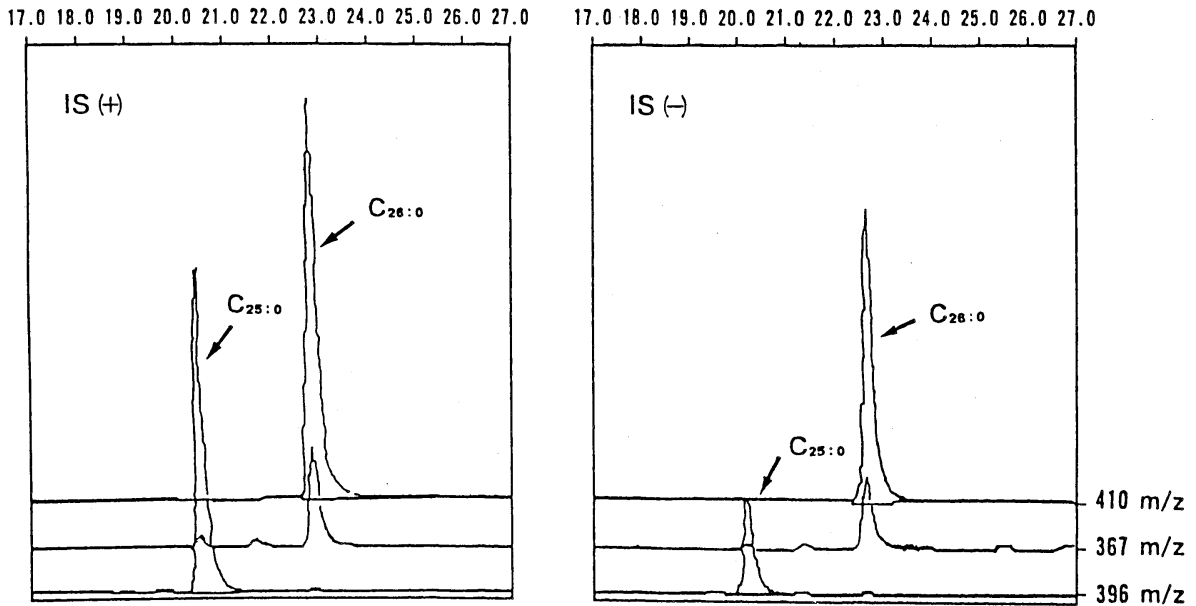

Fig. 2. One example (yogurt) of selected ion monitoring gas chromato-mass-spectra (IS, internal standard). 


\begin{tabular}{|c|c|c|c|c|c|}
\hline 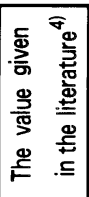 & 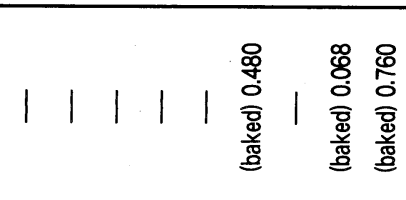 & 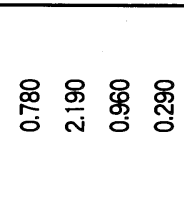 & | 怘 & 吕 焁 & ల్ల \\
\hline 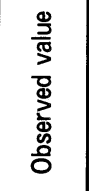 & 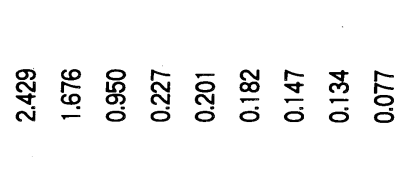 & 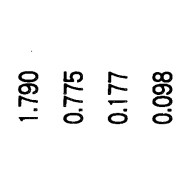 & సָ চ্ণু & 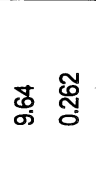 & $\frac{\sigma}{6}$ \\
\hline 운 & 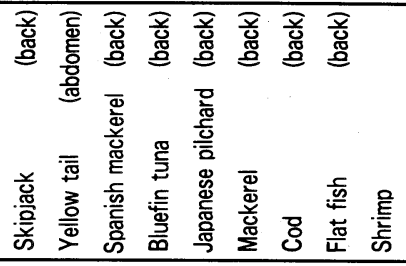 & 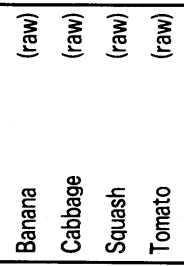 & 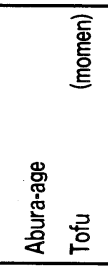 & 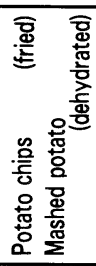 & 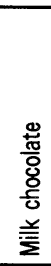 \\
\hline 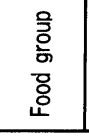 & 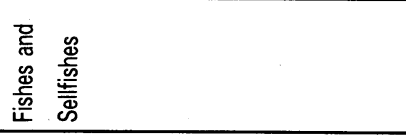 & 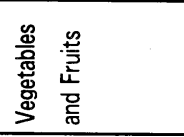 & 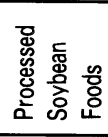 & 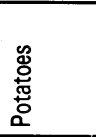 & 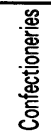 \\
\hline
\end{tabular}

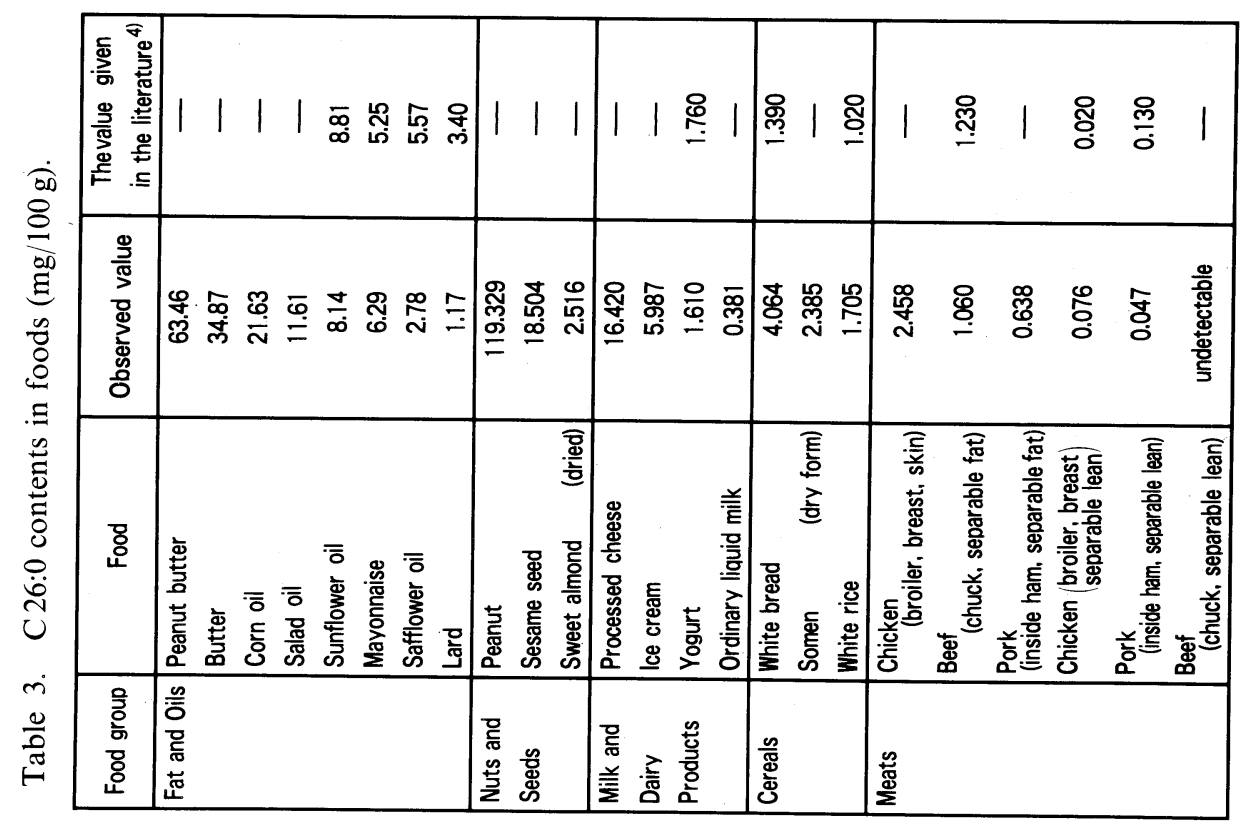


duplicate samples of methylesters of total fatty acids as prepared above were applied directly to a selected ion monitoring gas chromatography-mass spectrometry (SIM-GC-MS). The M-80B-type GC-MS instrument, Hitachi Co., was used in electron-impact mode, monitoring selected ions at $\mathrm{m} / \mathrm{z} 410$ (molecular ion of C26:0), $m / z 367$ (molecular ion of C26:0-43), and $m / z 396$ (molecular ion of C25:0). The OV-1 bonded capillary column $(0.25 \mathrm{~mm} \times 25 \mathrm{~m})$ of Gaskurokōgyo Co. and a split-less cooled-on-column injector of the Gaskurokōgyo Co. were used. The raising rates of column temperature were $30^{\circ} \mathrm{C} / \mathrm{min}$ between 85 and $250^{\circ} \mathrm{C}$ and $1^{\circ} \mathrm{C} / \mathrm{min}$ between 250 and $270^{\circ} \mathrm{C}$. The MS was operated at an ionization voltage of $70 \mathrm{eV}$, an accelerating voltage of $3 \mathrm{~V}$, and an ion source temperature of $210^{\circ} \mathrm{C}$. Calibration curve for quantitative analysis of $\mathrm{C} 26: 0$ was made by plotting the peakarea ratio $(m / z 410 / 396)$ against the weight ratio (MeC26:0/MeC25:0), as shown in Fig. 1. The real peak-area ratio $(m / z 410 / 396)$ was calculated by the formula shown in Table 2 where $a$ and $b$ represent apparent area ratios obtained by SIM-GC-MS with methylesters of total fatty acids in the presence and absence of internal standard (C25:0), respectively. One example of SIM-GC-MS is shown in Fig. 2.

\section{RESULTS}

The C26:0 contents $(\mathrm{mg} / 100 \mathrm{~g}$ food) in foods examined by procedures as described above are shown in Table 3. The data of Van Duyn group (4) on the food items which were the same as ours are also presented in that table. Among the examined foods, peanuts have the highest content (much higher than any others), and many kinds of fats and oils, cheese, potato chips, milk chocolate, ice cream, and bread have relatively high contents. Fishes have generally low contents. Comparing our data with that of Van Duyn group (4), C26:0 contents in about half of the food items (sunflower oil, mayonnaise, yogurt, etc.) are similar whereas in the other items (safflower oil, lard, cabbage, tofu, etc.) they differ.

\section{DISCUSSION}

Before our present work, Van Duyn group (4) reported the C26: 0 contents in 135 American food items. However, their study did not include some Japanese common foods, especially several kinds of fishes. Accordingly, C26:0 contents in Japanese common foods were measured. The method used for preparing methylesters of total fatty acids from food is a very convenient one from the viewpoints of both precision and time-saving. The SIM-GC-MS for quantitative analysis of $\mathrm{C} 26: 0$ in the methylesters of total fatty acids is also a well-known procedure as the most rapid, accurate, and sensitive method. As shown in Table 3, some of our data do not coincide well with those of Van Duyn group(4). The reason for the discrepancy is not clear at present, because many experimental conditions, for example, measuring method, food-producing place, food-processing, etc., differed. It is conceivable that contents of some elements in foods might vary depending on 
the place produced, especially if the distance were considerable.

From data presented here and the national nutrition survey in 1986(8), the daily intake of $\mathrm{C} 26: 0$ from the average Japanese diet could be estimated to be 12$36 \mathrm{mg}$, which is close to that from American diet (15-40 mg intake). Moser's group (6) achieved significant reduction in plasma VLCFA levels of 25 out of 36 ALD patients with a daily diet enriched in C18:1 (45-90 ml of glyceryl trioleate oil containing about $90 \%$ of $\mathrm{C} 18: 1$ ) along with a restriction in $\mathrm{C} 26: 0$ below $10 \mathrm{mg}$ for about a hundred days. Presumably C18:1 competed with saturated fatty acids for their microsomal chain elongation system. Now, we can recommend that, beside the oleate-enrichment as described above, nuts and seeds as well as fats and oils should be restricted as severely as possible from the diet of ALD patients in Japan also, in order to keep daily C26:0 intake below $10 \mathrm{mg}$ as recommended by Moser's group (6). We hope our present data will prove beneficial in the treatment of ALD as well as other VLCFA-accumulating disorders in Japan and other countries which consume food items similar to the ones in our study.

\section{REFERENCES}

1) Goldfischer, S., Collins, J., Rapin, I., Coltoff-Schiller, B., Chang, C. H., Nigro, M., Black, V. H., Javitt, N. B., Moser, H. W., and Lazarow, P. B. (1985): Peroxisomal defects in neonatal onset and X-linked adrenoleukodystrophies. Science, 227, 67-70.

2) Hashmi, M., Stanley, I., and Singh, I. (1986): Lignoceroyl-CoASH ligase: Enzyme defect in fatty acid $\beta$-oxidation system in X-linked childhood adrenoleukodystrophy. FEBS Lett., 196(2), 247-250.

3) Kishimoto, Y., Moser, H. W., Kawamura, N., Platt, M., Pallante, S. L., and Fenselau, C. (1980): Adrenoleukodystrophy: Evidence that abnormal very long chain fatty acids of brain cholesterol esters are of exogenous origin. Biochem. Biophys. Res. Commun., 96, 69-76.

4) Van Duyn, M. A., Moser, A. E., Brown, F. R., Sacktor, N., Liu, A., and Moser, H. W. (1984): The design of a diet restricted in saturated very long chain fatty acids: Therapeutic application in adrenoleukodystrophy. Am. J. Clin. Nutr., 40, 277-284.

5) Rizzo, W. B., Phillips, M. W., Dammann, A. L., Leshner, R. T., Jenning, S. S., Avigan, J., and Pround, V. K. (1987): Adrenoleukodystrophy: Dietary oleic acid lowers hexacosanoate levels. Ann. Neurol., 21, 232-239.

6) Moser, A. B., Odone, A., Naidu, S., Cornblath, D., Sanders, D. B., and Moser, H. W. (1987): A new dietary therapy for adrenoleukodystrophy: Biochemical and preliminary clinical results in 36 patients. Ann. Neurol., 21, 240-249.

7) Lepage, G., and Roy, C. C. (1986): Direct transesterification of all classes of lipids in a one-step reaction. J. Lipid Res., 27, 114-120.

8) Health Promotion and Nutrition Division, Health Service Bureau Ministry of Health Welfare (1988): National Nutrition Survey 1986. The Nutr. Jpn., 31, 21-29. 